\title{
Reflections on Police Reform
}

In this concluding chapter we first summarize the principal findings of our research and the contributions to knowledge that the findings represent. We then consider the implications of the findings for: (1) understanding procedural justice and police legitimacy; (2) police efforts to promote public trust and confidence; (3) police reform more generally; and (4) future research on procedural justice.

\section{WHAT WE FOUND}

Our analysis of Schenectady rests on a broader foundation of data, including not only the survey data on citizens' satisfaction and their judgments about the procedural justice of the police in their contact, and the interviews with commanders, patrol supervisors, and patrol officers, but also the observations of police-citizen encounters and the direct comparison of subjective experience and officer behavior. So we begin with what we take to be the principal findings from Schenectady, and then we consider the respects in which those findings are corroborated (or contradicted) by the findings from Syracuse.

In Schenectady, we observed moderate levels of procedural justice and low levels of procedural injustice in officers' behavior. These findings are not directly comparable to those of Jonathan-Zamir, Mastrofski, and Moyal, who constructed a single measure of procedural justice/injustice, and whose research was conducted in a suburban jurisdiction that they describe as a "professional, well-trained police agency, with leaders committed to several of the currently popular progressive police reforms, such as community and problem-oriented policing" $(2015,865)$. Insofar as comparisons can be drawn, officers in both Schenectady and "Everdene" 
exhibited procedural justice that varied across the procedural justice domains, and which was overall moderate. In Schenectady, we found low levels of procedural injustice.

We found that officers' patterns of procedural justice and procedural injustice are shaped in important ways by elements of the situations in which officers become involved and the behavior of citizens with whom officers interact. Procedural justice was greater in incidents that involved violent crime or interpersonal conflict, greater when the citizen was black, lower when the citizen was a suspect or third party rather than a victim or complainant, and lower when the citizen resisted the officer's authority. Procedural injustice was greater when the citizen was male, a suspect, intoxicated, resisted police authority, or disrespected police; injustice was lower when the citizen was black. As Jonathan-Zamir, Mastrofski, and Moyal did in Everdene, we can see room for improvement in the level of procedural justice in Schenectady, but such improvement might not be instrumental in improving either citizens' subjective experience or, through that experience, public trust and police legitimacy.

Citizens' subjective experiences are rather weakly related to the forms of officers' overt behavior that comprise procedural justice. Officers' procedural justice and injustice together explained no more than 12 percent of the variation in citizens' subjective experience in Schenectady. Procedural injustice had the greater effect on subjective experience, by far, such that we found asymmetry in the effects of justice and injustice that parallel previous findings based only on survey data. However, the Schenectady data suggest that this asymmetry stems not from the relatively strong effects of negative experiences but rather from citizens' tendency to overestimate the procedural justice with which police act in their encounters. The relationship between officers' procedural justice and citizens' subjective experience is weak partly because citizens tend to be fairly positive in their ratings of police performance, even when the procedural justice that we observed was fairly low. This pattern probably reflects the impact of citizens' more general attitudes toward the police on their perceptions of police actions in individual encounters with police. ${ }^{1}$

Citizens' judgments about procedural justice are also affected by whether (if not so much how) officers exercise forms of police authority: conducting searches or using physical force. Searches of citizens have strong effects on their assessments of procedural justice, unless citizens accede to them, while the use of physical force (but not verbal force) has a substantively notable effect as well. We have treated these forms of behavior as distinct from procedural justice as such. We believe that this treatment is consistent with the best judgments in previous research (which displays no consensus on these matters) and with the procedural justice model, which correctly holds that tough enforcement can nevertheless be fair (Schulhofer et al. 2011). We did not make a distinction between legal and illegal searches, nor did we make a distinction between reasonable and unreasonable force, but extant 
evidence suggests that citizens' judgments about the propriety of police action turns on their perceptions of procedural justice and not on the legality of officers' behavior, per se (Meares et al. 2012).

In this connection, we would note that unfavorable subjective experiences are more prevalent in police-initiated contacts but certainly not confined to those contacts. In fact, given the volume of citizen-initiated contacts through calls for service, in a fraction (about 15 percent) of which citizens judge procedural justice unfavorably, negative subjective experiences are more numerous, in absolute terms, in citizen-initiated contacts.

Neither indicator of police performance-a survey-based indicator or an observation-based indicator-revealed consistent changes that ensued from the survey-based measurement of performance. Overall, the month-to-month changes in measures of citizens' subjective experience were by and large within a range of sampling fluctuation, and with no change that could be attributed to the introduction of performance measures to monthly Compstat meetings. Given the weak connections between what officers do (and do not do) and what citizens later think about it, we might well see little or no change in survey-based measures of performance with good faith-even herculean-efforts by platoon commanders and field supervisors to manage their officers' behavior in police-citizen encounters. But neither did we see consistent changes in the observation-based measures of officers' procedural justice.

However, platoon commanders and especially first-line supervisors approached the management of this police outcome in different ways, which we characterized as forming a continuum. Some gave regular attention to the quality of policecitizen interaction during line-ups, and in that context shared survey results that had been delivered at the monthly Compstat meeting. They explained both what procedural justice means and why it is important. On one platoon, this appeared to affect officers' performance. On others, however, commanders and supervisors either attended to the issue only intermittently, alluding to what it means for officers' conduct but not its rationale, or were skeptical or even dismissive of the importance of "customer service."

This continuum reflects "sensemaking" by Schenectady's sergeants-that is, interpretation of what customer service or procedural justice represents and the appropriate emphasis to be placed on the quality of police-citizen interactions in the context of the demands of street-level police work. Based on their interpretations, some were receptive to the administration's emphasis on "customer service," finding it quite appropriate, while others were more guarded in their willingness to embrace the idea, or flatly opposed to it. This same process of sensemaking played out among patrol officers.

In Syracuse, we found patterns very similar to those in Schenectady on every score that we were able to measure. Citizens' subjective experiences were of 
a generally comparable nature, and they tended to bear the same relationships to other factors, including legitimacy, even though legitimacy was somewhat higher in Syracuse than in Schenectady. We also found similar patterns of variation in the management of procedural justice, and similarly mixed receptivity to a customerservice emphasis among patrol officers and supervisors.

No one study can be definitive on any question of social cause-and-effect, and no pair of police departments can be taken as representative of American police organizations, so firm conclusions will await replication of this study, but we can address some issues concerning the generalizability of these findings. We would observe, first, that if mid-level managers and frontline supervisors in mid-sized departments like Schenectady and Syracuse exhibit diversity in their interpretations of and support for a procedural justice model, we can safely anticipate that in larger agencies, mid-level managers and frontline supervisors will also diverge in the extent to which they embrace and actively manage the procedural justice with which their subordinates act, even when this outcome is measured on a regular basis.

Second, insofar as the more complete story could be told about the Schenectady police, whose officers' behavior we could observe through its video and audio recordings, we should be cautious in generalizing in view of the department's recent history and efforts to escape that history. The misbehavior of some Schenectady police officers was well publicized in local media, and a DOJ investigation suggested that the department suffered not only from its inability to terminate some sworn miscreants but also from systemic administrative deficiencies; the city's mayor openly considered disbanding the department. Be that as it may, scores on the trust index among Schenectady survey respondents were not very much different from those for the presumptively more typical Syracuse Police Department, and patterns of subjective experience were not much different across the two study departments.

Might the performance of Schenectady police have been elevated by the introduction of in-car cameras? The adoption of in-car cameras could be expected to improve the department's legitimacy, if only as a visible organizational reform and even if the operation of cameras was only loosely coupled with day-to-day police work. We cannot say whether and, if so, how much the introduction of cameras altered the routine performance of Schenectady police. Cameras were a matter of procedure that applied to all patrol units, day-in and day-out, and to which we believe (but cannot demonstrate) officers had become accustomed. In any case, we found only moderate levels of procedural justice and low levels of procedural injustice by officers as cameras rolled. Only their (infrequent) injustice had detectable effects on citizens' subjective experience. We would not suppose that procedural justice would be better managed in the absence of cameras, or that it would have greater effects on citizens' subjective experiences. Whether procedural justice 
could be better managed by making more extensive use of camera recordings is a question that we consider below.

\section{An Institutional Perspective}

Institutional theory is useful in understanding how the administrative emphasis on customer service in Schenectady and Syracuse was-and was not-translated into policing on the street, and more generally how the procedural justice model is likely to fare in police departments. This perspective directs our attention, first, to the fact that police work is comprised of a variety of functions, all or many of which are performed in a task environment that is heterogeneous, ambiguous, uncertain, and dangerous. The situations in which police intervene are complex. The goals of policing, and the information on the basis of which officers must make decisions, are ambiguous. The outcomes of alternative courses of action that officers might choose are uncertain. And in even the more seemingly mundane matters to which police attend a deadly risk is a part of the background. The technology of policing - that is, how the raw materials of citizens and their problems or behaviors are transformed into organizational outputs - is inevitably "intensive" (Thompson 1967), requiring that officers assess the many contingencies in a situation, choose a course of action on that basis, assess the immediate consequences of that choice, and potentially make additional and different choices as required. The tasks and technology of policing call, then, for the kind of discretion and judgment that society vests in occupations that are professions in every sense of the word such as medicine or law. Indeed, the analogy between policing and medicine has frequently been drawn: both call for diagnostic skills and for prescription in order to remedy a problem.

The professionalization of police produced not true professionals, however, but rather police bureaucracies (partially) insulated from their political environments (Brown 1981). A Weberian bureaucracy is well suited for industrial settings that apply an assembly-line ("long-linked") technology to standardized raw materials, and where the task environment is homogeneous, the procedures for transforming raw materials into work products are well understood and can be specified in advance. But the same bureaucratic form is not so well suited for policing. Insofar as the bureaucratic structure conflicts with the nature of the work-the "technical core"-it is loosely coupled with what officers do. Michael Brown argues that the bureaucracy has actually made matters worse, in that a punitive system of supervision has amplified the uncertainties with which officers must cope. Notwithstanding these contradictions, however, the bureaucratic form has remained, as constituencies inside and outside policing take for granted that it is appropriate.

Recent reforms-community policing, public accountability mechanisms, and Compstat-have been superimposed on the existing structures, in spite of the fact that they are themselves not entirely compatible with the technical core, with the 
existing bureaucratic organization, and/or with one another. Community policing is in fact compatible with the work that police do, though not with the crimefighting emphasis that was incorporated into the professional model, and even as community policing advocates sought to expand the police role, such that its success would not turn on its effect on crime, we are consistently drawn like a moth to flame to ask whether community policing reduces crime. Partly as a consequence, community policing has been a tough sell with the rank-and-file. Insofar as the profound structural changes that community policing requires have not been made, implementation has been shallow.

Public accountability through citizen oversight has left complainants unhappy and its advocates disappointed, and it appears that it has left officers largely unaffected in how they go about police work. More recent efforts to promote police accountability turn largely on administrative rule-making, which is compatible with the facets of police work that are also most compatible with the bureaucratic model: wherever police administrators can specify the circumstances under which police authority should or may not be exercised (e.g., arresting spouse abusers and not shooting at fleeing felons, respectively) and administrators can enforce compliance with the rules (i.e., sanction noncompliance). Many of the routine choices that police must make are beyond the reach of administrative rules, though it is possible that policies governing the use of less-lethal force could be coupled with police practice to the benefit of police and citizens alike, a possibility that we consider below.

In the New York City Police Department, Compstat appears to have achieved a level of managerial accountability that stimulated greater attention to the ends, and not merely the means, of police work. Compstat-like mechanisms introduced in other agencies have not, however, emphasized accountability or led to innovative problem-solving.

Superimposed on existing structures, the procedural justice model is likely to be similarly loosely coupled with police practice. If procedural justice is not measured reliably (or at all), no one would need to confront the fact that procedurally just policing has not become routine practice. A procedural justice model, we learned in our interviews with patrol officers and supervisors, is incompatible with police work as some officers experience it. We doubt very much that this is simply a manifestation of generational or personality differences among officers. It is more likely, we believe, attributable to the nature of the work that police perform and the cultural norms that grow out of that work. It is still appropriate to observe, as Brown did more than three decades ago, that "if there is a lesson to be learned from the experiences of the most recent generation of reformers, it is that simply enveloping policemen in a maze of institutional controls without grappling with the grimy realities of police work does not necessarily promote accountability and may only exacerbate matters" $(1981,303)$. Moreover, there is good reason to doubt 
that the practice of procedural justice by police in citizen encounters will substantially affect citizens' subjective experiences and, consequently, improve police legitimacy.

We should add, in this connection, that if a key element of the procedural justice model is the "organizational justice" with which police departments treat officers, it implies internal structures that depart from current structures in some important respects, and whose effects on officers' perceptions and behavior are open questions. Some empirical evidence suggests that the procedural justice with which a police agency is perceived by its officers to operate affects officers' views of the agency's legitimacy, and legitimacy in turn shapes officers' conformity to organizational regulations (Tyler, Callahan, and Frost 2007; Wolfe and Piquero 2011). This evidence is consistent with a claim made long ago that police officers' treatment of citizens is influenced by the police department's treatment of its officers (Guyot 1991). However, we have to allow for the possibility that officers' perceptions of organizational justice are as weakly connected to the actual administrative practices of police departments as citizens' perceptions of procedural justice are to the behaviors of police officers that comprise procedural justice. Altering the internal structures of police departments to better conform with principles of procedural justice may well have many benefits, but improvements in legitimacy and officer performance might not be among them.

We might also add - though our point is based on only casual observationthat police executives' interest in private-sector management prescriptions should be tempered by a careful consideration of the respects in which those prescriptions apply to police organizations. We have, for example, heard police chiefs talk enthusiastically about the $\mathrm{Oz}$ Principle (Connors et al. 2004), the three laws of performance (Zaffron and Logan 2011), and the Six Sigma methodology. (With the assistance of General Electric, Schenectady police command staff were trained in Six Sigma.) The analysis and advice that managers find in these sources might well be helpful, but they should not presume that what works effectively in manufacturing or other private-sector organizations will work equally well in the police environment.

\section{IMPLICATIONS}

\section{Understanding Public Attitudes and Procedural Justice}

One implication of the findings reported here for understanding public trust in police and procedural justice is that it is imperative to draw a sharp distinction between procedural justice as citizens' subjective experience and procedural justice as officers' overt behavior. They are different phenomena, even if we can use the same conceptual framework to define and operationalize them. Most previous research has relied on surveys of citizens to measure procedural justice, and most 
previous research on police behavior has not measured procedural justice. Using survey and observational methods to measure both citizens' perceptions and officers' behavior, respectively, we find the former are not straightforward reflections of the latter.

We already knew that citizens' judgments about procedural justice, and their satisfaction, in police-citizen encounters are very much subjective. But we may have underappreciated the degree to which they are subjective. Most survey research is cross-sectional; panel surveys are difficult and expensive to execute. But the handful of panel surveys show not only that subjective experience affects global attitudes toward the police, including trust and confidence, but also and especially that global attitudes have a large bearing on subjective experience. These reciprocal effects are far from balanced. What citizens take away from their encounters with the police in the form of their attitudes toward the police is shaped by what they brought to their encounters much more than by what police do. Citizens' subjective experience with the police is also influenced by broader contextual frames, such as the reputation of the police department and (for blacks) a history of discrimination, and by citizens' related interactions with personnel from other agencies, such as 911 center dispatchers or jail staff in booking facilities. Only a small fraction of the variation in subjective experience is attributable to how officers at the scene actually act. From the relationships between citizens' perceptions of procedural justice and citizens' satisfaction or beliefs about police legitimacy, it is safe to draw only inferences about the connections among these outlooks and not inferences about how these outlooks are shaped by what police do.

In order to describe, analyze, and understand procedural justice as it is enacted by police, it is necessary to observe it directly (in person or through recordings). We cannot rely on citizens' responses to surveys. Systematic social observation is a well-established method for measuring police behavior, and it can certainly be adapted to the measurement of procedural justice by police. Doing so potentially opens an analytic door to answering a wide range of questions about the levels of procedural justice that prevail in police-citizen encounters and the forces that influence procedural justice by police-all of the situational, individual, organizational, and community factors that have been examined in extant research on the use of police authority (see Worden and McLean 2014b).

\section{Creating Police Legitimacy}

If future research replicates our findings from Schenectady concerning the relationship of citizens' subjective experience to officers' procedural justice, then our interpretation of survey-based measures of the quality of police performance in citizen encounters must be more circumspect. From this analysis it appears that subjective assessments do not reflect officers' performance very well. The surveybased procedural justice index varied with the nature of the contact (a call for 
service or a police-initiated contact) and the forms of authority that police exercised, but it varied with procedural justice mainly insofar as officers behaved in procedurally unjust ways, and overall procedural justice and injustice together accounted for little of the variation in citizens' judgments. Encounters in which officers performed very well in terms of conforming to principles of procedural justice-such as explaining their actions or listening to citizens-were not much more likely to yield positive assessments by citizens than encounters in which officers did not exhibit procedural justice. As a source of information about how well officers perform in procedural justice terms, it appears that citizen surveys-even surveys of people involved in recent contacts documented in police records-are of very limited utility.

That citizens' responses to surveys do not reflect officers' behavior very accurately does not mean that the measures derived from citizen surveys are useless. Whether they are firmly or only weakly rooted in officers' actions, citizens' perceptions are real, and their consequences are real too. Public trust is important for police. We think it likely that police departments benefit from higher levels of public trust and confidence. Police officers may benefit when their departments enjoy higher levels of public trust, insofar as citizens are more likely to be compliant in individual police-citizen encounters, and more likely to be cooperative in providing information and otherwise "coproducing" community safety by working with police. Efforts by a police department to build its stock of public trust can be expected to redound to the department's advantage and its community's benefit.

But it does not appear that police can do much to "create" legitimacy through the procedural justice of their day-to-day interactions with citizens. Officers can detract from public trust at the margin by acting with procedural injustice. But they add if at all only imperceptibly to public trust by acting with greater procedural justice. For example, and more particularly, when police conduct a stop, and when they conduct a frisk or search during that stop, the citizen's subjective experience is unlikely to be affected for the better when the officer takes affirmative steps to be procedurally just. In general, police may be able to influence, but they do not control, any of the outcomes that really matter-crime, disorder, citizen satisfaction-because these are also influenced by many other social forces. Successful efforts to influence public trust will consist mainly of measures other than managing the procedural justice of street-level behavior.

That public trust does not turn to a meaningful degree on managing street-level procedural justice might be good news, insofar as what gets measured does not always get managed, at least not in an institutionalized organization. In a bureaucracy-even a paramilitary bureaucracy - in which the task environment is ambiguous and uncertain, mid-level managers and frontline workers must interpret agency mandates against the imperatives of the work as they understand them. This can result in loose coupling between the practices that management espouses and the practices that are 
applied on the street and that represent, in the aggregate, the service delivered by the agency. In an agency that publicly espouses an approach that highlights the value of procedural justice, but in the absence of reliable measures of actual performance in those terms, there might well be a wide divergence between the public pronouncements by the agency and its day-to-day performance on the street. But it would be a divergence about which agency managers could remain blissfully ignorant. The public pronouncements might add to the department's legitimacy, in that they signal an appreciation by department leaders that it is important. But the decoupled technical core would continue unaffected.

We hasten to add that we do not mean to imply that the adoption of structures that serve institutional purposes therefore do not and cannot serve more conventional technical-rational purposes in an organization, and even if the structures serve only more symbolic purposes, it does not follow that their adoption was an act of administrative duplicity. We do not doubt that when police executives adopt community policing, or early intervention systems, or Compstat, for example, they do so in good faith to achieve the instrumental benefits they promise, but structural features of policing and police organizations undermine these measures.

Officers' views on how they should do their jobs, particularly how they should interact with citizens, mediate the implementation of a procedural justice model of policing, and many officers in the study departments did not embrace procedural justice concepts, even though our observations indicated that Schenectady police performed fairly well in procedural justice terms. Officer safety is an overriding consideration, and given the structural forces that understandably make safety a high priority, it is likely to remain so; managerial efforts to alter this feature of police culture have not been promising.

Like street-level personnel, managers must also interpret agency mandates and whether and how to manage the things that get measured. Crime has been measured as a part of the Uniform Crime Reporting system for decades, and yet as the newly appointed commissioner of the NYPD, William Bratton found it necessary in 1994 to reengineer the department to prompt police managers to embrace (or "own") crime-fighting as a responsibility. Measuring valued outcomes is almost certainly necessary, but it is not sufficient.

It might be possible for police administrators to exercise more control over officers' procedural justice, in spite of the shortcomings of citizen surveys as a performance indicator, by making use of in-car and body-worn cameras to extend the capacity of the bureaucracy to monitor officers' performance. Just as police-recorded video (and especially audio) enabled us to conduct armchair observation of police-citizen encounters, in-car and perhaps especially body-worn cameras enable police supervisors to monitor their subordinates' performance as never before. We know of only anecdotal evidence, but it is likely that the availability of video has already improved the capacity of internal affairs investigators to 
sustain or unfound complaints about discourtesy (though discourtesy is ambiguous). Field supervisors in urban departments have always been able to observe officers' behavior directly, but they had to be strategic about it, since the number of subordinates for whom a supervisor is responsible and their dispersion across the precinct's landscape requires supervisors to pick and choose whom they observe and when. Police video introduces a whole new supervisory calculus.

But the obstacles to direct supervision have not been merely logistical. In many departments a strong norm of autonomy holds. Once rookie status is shed, officers expect to be treated like professionals, with a measure of deference to their competence and judgment. It is one thing to review recordings of police-citizen encounters to investigate allegations of misconduct, or to more proactively scan for major violations of departmental procedure, but it is another to micromanage officers' interactions with citizens. As Brown observes, "the animosity that some patrolmen display toward a supervisor who attempts to monitor closely their actions and the reluctance of many supervisors to interfere with patrolmen stem largely from the force [of the norm prohibiting such second-guessing]" (1981, 90). Technology is adapted to organizational settings more than organizational settings are adapted to technology (though typewriter manufacturers may disagree with us), and so we doubt that body-worn cameras are about to usher in a new era of scientific police management based on the procedural justice analogs to Frederick Taylor's time-and-motion studies.

Consider another street-level bureaucracy, schools. School administrators are much better able to observe teachers' classroom performance directly than police supervisors have been able in the past to observe officers' performance, Nevertheless, teachers have enjoyed a great deal of autonomy, and administrators display what educational researchers have characterized as a logic of confidence: an assumption that teachers are doing what they should be doing and that the organization is functioning as it should be (Eden 2001; Elmore 1999; Meyer and Rowan 1978).

If police departments choose to use cameras to monitor the procedural justice with which officers act, they have several options. They could actively monitor officers' behavior, sanctioning officers who violate department procedures when they engage in some forms of procedurally unjust behavior (whether or not a citizen complains about it), and coaching officers whose performance leaves room for improvement with respect to procedural justice. They could even try to establish and apply a standard of workmanship (Bittner 1983) that incorporates procedural justice, though they probably could not require that officers meet that standard. Alternatively, departments could more passively monitor officers' behavior, reviewing camera recordings only when officers' behavior is called into question; this would leave the cameras more loosely coupled with routine police practices. Based on our findings, we think it likely that merely providing for cameras would 
contribute as much to police legitimacy as active monitoring, since any improvement in officers' procedural justice is unlikely to yield corresponding improvements in citizens' subjective experience and police legitimacy.

More generally, it appears that organizational reform is a more promising approach to building police legitimacy than managing procedural justice in policecitizen encounters. ${ }^{2}$ The reforms that we reviewed in chapter 2-community policing, early intervention systems, Compstat-have probably done more than street-level procedural justice could to increase the legitimacy of the agencies that adopted them, even if the reforms were weakly implemented and loosely coupled to the technical core of policing. Other reforms that might be expected to improve police legitimacy include personnel practices that are designed to provide for greater congruence between the composition of police departments and the communities they serve (National Research Council 2004, 312-14), educational requirements and training (Gau 2014, 3364), and proactively disseminating information to the public and managing media relations (Gau 2014, 3365). Let us take a closer look at some of these possibilities.

\section{Implications for Police Reform}

Piecing together the findings of our inquiry, extant research on policing, and clues about successful police reforms, we can cautiously trace some implications for contemporary reform. Let us begin this exercise by considering the case of reform in Cincinnati, where rioting followed the fatal shooting of an unarmed black teenager by police in 2001, after fourteen black men-but no whites-had died in police deadly force incidents since 1995 (Fisher 2014). Cincinnati's mayor requested a federal investigation of the Cincinnati Police Department's use of force, an investigation that culminated in a memorandum of agreement (MOA) that stipulated a number of reforms (Schatmeier 2013). Among other changes, the MOA required that CPD revise its policies governing the use of force to provide for a force continuum, to require documentation of every use of force, and to require on-scene investigation of uses of force by a supervisor (Memorandum of Agreement 2002). The MOA also established a Citizen Complaint Authority and required measures designed to facilitate the filing of citizen complaints against the police and to better ensure the participation of civilians in their review. It further mandated the establishment of a risk-management system (i.e., an early intervention system). In these respects, the MOA resembled the public accountability reforms described in chapter 2 as features of the institutional environment of police departments. The implementation of the reforms-achieving "substantial compliance"-was overseen by a court-appointed monitor from 2002 until 2007.

But in addition, Cincinnati police also entered into a "collaborative agreement" with parties to a lawsuit that had been filed in federal court prior to the DOJ investigation, including the American Civil Liberties Union, the Fraternal Order of 
Police, and the Cincinnati Black United Front (Schatmeier 2013). The collaborative agreement, as an alternative resolution of the suit's claims, provided for CPD's adoption of community- and problem-oriented policing (CPOP). In particular, for example:

The Parties, and especially the CPD, understand that fully engaging the community is a fundamental key to effective law enforcement. The CPD will continue to implement policies and procedures that are guided by the principles of community problem-oriented policing. In accordance with these principles, the CPD continues to work in partnership with the community to solve problems that impact the community. (In re Cincinnati Policing 2003, 7)

Both agreements were overseen by the same court-appointed monitor, though the collaborative agreement also provided for the selection of an independent evaluator. The RAND Corporation was selected and, among other things, conducted two surveys of the community-one in 2005 and a second in 2008-and also analyzed police-citizen interactions in annual samples of traffic stops across four years by coding the audio and video recordings captured by CPD's in-car cameras (Ridgeway et al. 2009; also see Dixon et al. 2008).

The surveys of the community-surveys of the general population and not of people with police contact-showed modest improvement in the public's assessments of "police professionalism," that is, judgments about whether police treat people with dignity and respect, are polite, apply the law fairly, consider people's views when making decisions, and so forth. On a scale that combined eight such survey items, the mean for blacks in 2005 was about 2.4, 0.6 lower than that for others, but still above 2.0, which signified generally favorable judgments. By 2008 , the mean for blacks had increased 0.15 along this four-point scale, a small (but statistically reliable) increase, while the mean for others was unchanged.

RAND's analysis of interactions in traffic stops found a number of racial disparities in the invasiveness of traffic stops-in the likelihood of a search and the duration of stops, for example. It also examined the quality of communications, finding that "the best predictor for good officer communication was good driver communication, and vice versa" (Ridgeway et al. 2009, 83). RAND found some evidence of change over time in the quality of officers' communication: "the observers rate them as better at listening to what the drivers say, as well as showing more patience and helpfulness in 2007 than in 2005 " $(2009,86)$, though the magnitude of the improvement is not specified.

Moreover, as recent studies have shown, the use of force by Cincinnati declined, not only for the duration of the federal monitoring but thereafter. Joshua Chanin shows that the use of force by Cincinnati police dropped 46 percent between 2002 and 2012, even as crime remained stable, and officer injuries dropped by more than half; in addition, citizen complaints declined. Thus, as Chanin points out, "six years removed from DOJ and monitor oversight, the Department 
has experienced little or no backsliding, a finding supported by consistent reductions in undesirable outcomes, including use of force incidence and allegations of abusive or unlawful behavior. In short, the reform effort in Cincinnati appears to have transformed the CPD" (2015, 179-80).

Indeed, a Washington Post article, written in the aftermath of the death of Michael Brown in Ferguson, Missouri, identified the CPD as a department whose practices might be worthy of emulation (Fisher 2014). No one claims that all is well in Cincinnati. RAND's surveys documented a persistent-albeit somewhat narrower-racial gap in public trust. And in 2014, the Post journalist observed that "mistrust of police in Cincinnati-even after full-scale retraining and a 120-point catalogue of altered procedures-remains palpable in black neighborhoods." But he also said that "thirteen years after riots that threatened to wreck Cincinnati's reputation and economy, many here say the police have become gentler, smarter, more transparent and more targeted in how they go after bad guys."

Pinpointing the specific reform(s) that deserve credit for these changes is impossible, but based on extant theory and evidence about police behavior, management, and community relations, we suspect that a lot of credit should be given to use-of-force policies and procedures that would seem to have been at least moderately coupled with street-level practice, and to the adoption of community and problem-oriented policing. The decline in the incidence of physical force is stunning, and it is surely not due to commensurate declines in citizen resistance. Cincinnati police became more restrained in their use of force. Certainly this could be partly attributable to training that CPD delivered to its officers, including training for a cadre of volunteer officers who were to handle incidents involving the mentally ill. But a change of this magnitude seems unlikely to stem from only formal training; we think it more likely that more restrictive policies that were executed by supervisors made a very substantial difference. We interviewed a small nonrandom sample of CPD supervisors in early 2016, and while we certainly heard about a mix of supervisory approaches, we were impressed by those who took quite seriously their responsibility, not only for assessing their subordinates' compliance with CPD force policies, but especially for ensuring that their officers were using sound tactics that minimized the risk of resistance, force, and injury. We would not infer that the coupling of policy and practice was uniformly tight, but it appears to us to have been sufficiently tight to have some very beneficial impacts on police use of force.

That such coupling does not follow the adoption of such policies is evident from DOJ's investigation of the Ferguson police. Ferguson's policies resemble those of the CPD:

Under FPD General Order 410.00, when an officer uses or attempts to use any force, a supervisor must respond to the scene to investigate. The supervisor must complete a two-page use-of-force report assessing whether the use of force complied with 
FPD's force policy. Additional forms are required for ECW uses and vehicle pursuits. According to policy and our interviews with Chief Jackson, a use-of-force packet is assembled-which should include the use-of-force report and supplemental forms, all police reports, any photographs, and any other supporting materials-and forwarded up the chain of command to the Chief. (U.S. Department of Justice 2015, 38).

But in Ferguson, "supervisors do little to no investigation; either do not understand or choose not to follow FPD's use-of-force policy in analyzing officer conduct; rarely correct officer misconduct when they find it; and do not see the patterns of abuse that are evident when viewing these incidents in the aggregate" (38). Coupling use of force policy with street-level practice requires managerial commitment and effort, but the CPD's experience suggests that it is feasible.

The use of physical force by police is often a contentious issue. Reasonable force is to some extent a matter of interpreting ambiguous circumstances, and police and public interpretations tend to diverge. Few citizens who are subjected to the application of physical force by police consider it proper. Among our Schenectady respondents, we found evidence that suggests that the use of physical force by police detracts from citizens' judgments of procedural justice; the effect was not of sufficient magnitude to achieve statistical significance at conventional levels, perhaps because the use of physical force was very infrequent. Reductions in the use of force by police, these results imply, could do more to "create" legitimacy on the street than increases in the procedural justice with which officers act.

Further extrapolating from our findings, other research, and Cincinnati's experience with the use of force, we would speculate that similar benefits in public trust could follow from policies and supervisory oversight and instruction in conducting searches. The case law of search and seizure is complex. Jon Gould and Stephen Mastrofski (2004) examined the frequency with which officers conducted discretionary searches (beyond "plain view") and how often the searches were unconstitutional (based on a matrix of Fourth Amendment court rulings); they found that nearly one-third of the searches were assessed as unconstitutional. If we can generalize from Gould and Mastrofski's findings, it seems safe to project that close adherence to the law would reduce the frequency with which police search citizens. If we can generalize from the findings from Schenectady and Syracuse, fewer searches would yield an improvement in citizens' subjective experiences, again creating more legitimacy. If policies governing searches were as tightly coupled to police practice as use of force policies appear to be coupled to practice in Cincinnati, then the formulation and implementation of such policies would be a useful step in police reform.

Community and problem-oriented policing was another major component in Cincinnati's reform agenda. We discussed the appeal of community policing in the institutional environment, and surely this was no less true in Cincinnati than elsewhere. Community policing is procedurally just on a community scale: it gives the 
community voice in identifying the public safety problems about which it is most concerned, and signifies the commitment of the police to addressing the matters that would contribute most to community improvement, as the community sees it. Moreover, community policing need not be tightly coupled to day-to-day patrol and investigative practice in order to achieve these outcomes; even specialized community policing units can serve as a bridge between the police and the public, and mount problem-solving initiatives to address community concerns. That is, even loosely coupled community policing is not (necessarily) window-dressing.

In addition, we should recognize that public attitudes are likely to change only very slowly, if at all. Despite the advances that have been made in Cincinnati, public attitudes have been largely stable. That the change in blacks' attitudes toward the Cincinnati police that RAND detected in its survey results was greater than zero is unlikely the product of sampling artifacts. But the improvement was small- 0.15 on a four-point scale of police professionalism. Street-level practice, particularly with respect to the use of force, changed far more dramatically than public attitudes did.

\section{Future Research}

Whether these findings-some from one police department and others from two departments-are generalizable to other settings is an open question, to be answered by future research. One research question that we would nominate as a high priority for future research is the hypothesized relationship between officers' procedural justice and citizens' subjective experience. Clues that the relationship is fairly weak can be seen in previous research that has involved panel surveys, with estimates of the effects of prior attitudes toward police on satisfaction and/or procedural justice with individual contacts with police. But empirical evidence on this relationship that rests on measures of the two constructs-officers' procedural justice and citizens' subjective experience-drawn from independent data sources would be far preferable.

Research on officers' procedural justice need not extend to citizens' perceptions in order to be valuable, for much remains to be learned about patterns of procedurally just (and unjust) behavior. We might suppose that, like other forms of police behavior, procedurally just policing varies with the characteristics and behaviors of citizens and other characteristics of the situations in which police and citizens interact; the backgrounds and outlooks of individual police officers; the nature and intensity of the cues that officers receive from police administrators and supervisors about how they may and should treat citizens; and the community or neighborhood context for police-citizen encounters.

Extant research on police behavior sensitizes us to the ways in which officers' behavior is influenced by the features of the situations in which they interact with citizens. The use of police authority is shaped by both legal factors, such as the 
seriousness of the offense and the strength of evidence, and by extralegal factors, such as citizens' sex, demeanor, and (sometimes) race. We might especially expect that procedural justice-how police use their authority-would also be affected (but not determined) by the degree of respect and cooperation that citizens offer to police. Our examination of situational variables confirmed the hypothesized relationship of procedural injustice to citizen disrespect and resistance, though questions about causal order remained. Moreover, these variables accounted for only one-third or less of the variation in procedural justice or injustice.

Research on several forms of police officers' behavior-arrests, use of force, stops, and several forms of misconduct-all suggests that behavior varies among individual officers. For example, Samuel Walker $(2005,100)$ summarized several investigations that suggest that small numbers of officers account for disproportionately large fractions of citizen complaints and use-of-force reports. Steven Brandl et al. (2001) found that less experienced officers are disproportionately represented among officers with multiple complaints about the use of excessive force. Many years ago, Hans Toch (1980; also see Toch 1996) found that violence-prone officers are especially sensitive to citizens' challenges to their authority. Ellen Scrivner (1994) discovered five groups of officers among those referred to police psychologists due to their use of excessive force, including: officers with personality disorders; officers whose job-related experiences-for example, traumatic incidents such as police shootings-put them at risk for abusing force; young and inexperienced officers who were also "highly impressionable and impulsive"; officers who develop inappropriate patrol styles; and officers with personal problems. Christopher Harris (2010) showed that officers differ in their career "trajectories" of misconduct. Research persuasively confirms what many police officers and administrators have observed for themselves: that "operational styles" (Brown, 1981) and police dysfunctions vary across individual officers.

Recent research indicates that the traits, outlooks, and cognitive schema of officers may be important in understanding and explaining these individual variations. William Terrill et al. (2003) reported that officers whose occupational attitudes conform more closely to the tenets of the traditional police culture are more prone to the use of their coercive authority. ${ }^{3}$ Similarly, Eugene Paoline and William Terrill (2005) found that such officers are more likely to conduct searches during traffic stops. Matthew Hickman (2008) found that cynicism predicts "problem police behavior," while Michael Cuttler and Paul Muchinsky (2006) found that personality traits and work history predict "dysfunctional job performance." Other characteristics of officers-their race, sex, and educational background-have all been hypothesized to affect how officers do their jobs, though the evidence on these hypotheses is mixed and inconclusive (National Research Council 2004). In view of the findings that officers' choices about the application (and misapplication) of their authority in making stops, using force, and invoking the law are all 
shaped to a degree by individual factors, there is good reason to believe that many of these same factors may help to account for the procedural justice with which police authority is exercised. In particular, we might expect that the officers whose outlooks most resemble those of the traditional police culture, and those who are more cynical, would be those least receptive to a procedural justice emphasis. If so, then the contours of rank-and-file resistance to procedurally just policing would resemble those of resistance to community policing (cf. Herbert 2009).

Previous research shows not only that individual officers' behavior varies, but also that their performance varies: some officers perform better than others. This should come as no surprise, as it is surely true of any occupational group, but it is especially difficult to demonstrate empirically in policing because positive police performance is so difficult to conceive and measure. David Bayley and James Garofalo $(1987,1989)$ asked officers themselves to identify peers who they considered to be especially skilled in handling conflict; in the three NYPD precincts they studied, Bayley and Garofalo thereby identified a set of exceptionally skilled officers on whom they conducted systematic observations. They found that these officers exhibited somewhat distinctive patterns of interaction with citizens, particularly in situations that were potentially conflictual: they "tended to be more concerned to get the fullest possible picture [of the incident] and to find a longrun solution, especially one that satisfied the complainant, while [comparison officers] showed less sympathy for complainants' problems, and were quicker to say that the police couldn't do anything" $(1987,13)$. They added that the more skilled officers "offered more information about ways to resolve problems, while [comparison officers] lectured citizens about how to act in the future and threatened a stern response if they were called back" (13). While Bayley and Garofalo did not frame their analysis in the terms of procedural justice, we might retrospectively observe that the skilled officers acted in ways that independent observers would be likely to interpret as showing concern for citizens' needs and concerns, and affording citizens an opportunity to explain their situations.

In general, based on extant research, we might reasonably speculate that some officers perform consistently well in terms of procedural justice, either preventing citizen disrespect and resistance or responding to it with equanimity and professionalism, and otherwise exhibiting a high quality of decision-making; we need to learn from these officers what they do (and do not do) and why, which implies that we need to understand how officers perceive and interpret their encounters with citizens-the perceptual and cognitive processes that yield different reactions to similar stimuli-including how officers see the different clientele they serve, and whether/why some are more or less deserving of procedural justice. We might further suppose that typical or average officers sometimes perform poorly in procedural justice terms, and we also need to learn from these officers what they do (and do not do) and why. 
As Stephen Mastrofski et al. $(2002,542)$ suggest, the quality of police-citizen interactions might be influenced by administrators in one or both of two ways: obtrusive (or "bureaucratic") controls, such as rules, regulations, and sanctions for rule violations; and unobtrusive (or "professional") controls, such as training and socialization. As a practical matter, and for reasons that we explained in chapters 2 and 8 , the establishment of such practices is likely to progress unevenly across organizational units, managers, supervisors, and officers, such that we are likely to find variation not only in behavioral conformity with procedural justice but also in awareness, recognition, understanding, and acceptance of procedural justice concepts and principles.

Therein lies a key question: what accounts for the tighter coupling of policy and practice in some agencies - such as Cincinnati, perhaps-than in others-such as Ferguson? The question has been recently posed, but not answered, in connection with sustaining reforms wrought by consent decrees and settlement agreements, which coercively "unfreeze" an organization for change. But after the cessation of court-appointed monitoring, and the leverage that the court brings to bear to ensure that reforms are implemented is withdrawn, the coupling of the reforms may loosen, and the practices in which they are intended to result may lapse. How, if at all, can such reforms be installed in such a way that they will survive not only the discontinuation of court supervision but also administrative turnover?

Finally, while we believe that steps to better prepare officers to exercise their authority-including especially searches and the use of force-are the most promising avenues of police reform, extant research offers little evidence about how police organizations can effectively perform these functions. Training and supervision are frequently mentioned. Such prescriptions rest largely on logic and wishful thinking, and certainly not on social scientific evidence. Academics and practitioners alike frequently comment on the crucial role that frontline supervisors play, but studies of how they play it, and how well they play it, are rarely conducted. There are no simple, easy answers, to be sure, but there is no credit for asking the right questions either. 